Research Article

\title{
Material Selection of Green Design Processes for Car Body via considering Environment Property
}

\author{
Yongfeng Pu $\mathbb{i}$, Fangwu Ma $\mathbb{D}^{D}$, Lu Han, and Guowang Wang \\ State Key Laboratory of Automotive Simulation and Control, Jilin University, Changchun 130025, China \\ Correspondence should be addressed to Fangwu Ma; mikema@jlu.edu.cn
}

Received 10 July 2019; Revised 18 September 2019; Accepted 22 October 2019; Published 16 March 2020

Academic Editor: Gaetano Giunta

Copyright ( 92020 Yongfeng Pu et al. This is an open access article distributed under the Creative Commons Attribution License, which permits unrestricted use, distribution, and reproduction in any medium, provided the original work is properly cited.

\begin{abstract}
Facing serious environmental degradation and its resulting of climate warming, how to conserve energy and reduce emissions becomes a serious issue for government supervisors and modern vehicle enterprises. Reducing the mass of a vehicle is one of the most effective ways to reduce emissions and improve fuel utilization, essential to persist the low-carbon and sustainable-development bases in industrial production processes. When it comes to the selection of lightweight material for a car body in the processes of vehicle production, it is essential to comprehensively evaluate multiple relevant attributes in order to select the optimal material from several alternatives. Thus, it can be seen as a multicriterion decision-making (MCDM) problem. However, it is difficult to consider both the uncertainty of the expert's preference and the imprecision of the attribute estimate. Considering this, this paper uses the method integrating grey relational analysis (GRA) with analytic hierarchy process (AHP) to solve the problem of lightweight material selection for a car body. The AHP method is used to determine the weight of each attribute, and the GRA method is to select the optimal material among several alternatives. Finally, a case study is applied to verify the practicability of the proposed approach. The result shows that the proposed multicriterion decision method provides a precise and objective foundation for making decisions about the material selection issue.
\end{abstract}

\section{Introduction}

As the increasing vehicle economy presents the rapid speed of national development in recent years, the production and use of vehicles have increased sharply in China. China's autoproduction and sales have exceeded 10\% from 2008 to 2017, reaching 29.01 million in 2017 [1]. Simultaneously, the vehicle ownership in China has reached 240 million at the end of 2018, indicating a $10 \%$ increase over the past five years, from "China Vehicle Environmental Management Annual Report 2018" made by the Ministry of Ecology and Environment of the People's Republic of China [2]. The vehicle brings convenience to our daily life, but it also causes the problems of serious air pollution and resource shortage, which are now affecting human activities. Furthermore, China has become the world's largest vehicle production and sales country for nine years, while vehicle pollution has also become an important source and case of air pollution [1]. Therefore, the urgency of vehicle pollution prevention and control has become increasingly prominent.
Nowadays, with the formulation of emission laws and regulations in various countries, automakers are trying to bring three ways of innovations to enhance vehicle fuel efficiency, as well as reducing emissions during their use at the basic premise of specific vehicle performance. These methods can be summarized as follows: (i) improving drive train efficiency; (ii) designing new energy vehicles; (iii) replacing fuel systems or lightweight material replacement. Among them, the reduction of vehicle mass has been seen as one of the most effective solutions, thus gaining more and more attentions in automotive industries. The idea of vehicle light-weighting is to reduce the vehicle mass as much as possible, under the premise of guaranteeing the strength and safety performance of the vehicle. Then, improving the vehicle power, safety, and other comprehensive performance are used to achieve the purpose of energy saving and emission reduction. Generally speaking, a $100-\mathrm{kg}$ savings in vehicle mass will result in fuel savings of $0.3-0.6 \mathrm{~L}$ per $100 \mathrm{~km}$ and $0.85-1.4 \mathrm{~kg} \mathrm{CO} \mathrm{CO}_{2}$ per $100 \mathrm{~km}$ [2]. Although automakers have developed several technologies to improve 
the fuel economy of their vehicles, lightweight is still one of the preferred approaches. In order to reduce vehicle mass, several means of achieving automotive lightweight are applied, including application of lightweight materials, structural optimization, advanced manufacturing technologies, combination of these methods, and integrating parts and functions [3]. With the booming development of the automobile industry, the space structure and layout of the automobile body have been quite compact and reasonable, and the optimization technology of the automobile body structure has become increasingly mature [4]. Therefore, the development of lightweight material and advanced manufacturing technology will play a more prominent role in the material selection ways for the automobile industries. So the material selection of lightweight material has been widely used in automotive applications in recent years.

Material technology is the key to promote the technical progress of automobiles. Using lightweight materials is an important approach to ensure both the safety of automobiles and the reducing of body mass. At present, there are two main types of lightweight materials for automobiles: one is high-strength material, mainly referring to high-strength steel and advanced high-strength steel; the other is lightweight materials, mainly including aluminum alloys, magnesium alloys, plastics, and composite materials [5]. The using of suitable materials in the right place is significant. Therefore, it becomes a difficult issue for engineers to determine an optimal selection of materials considering multiperspective indices, which can be regarded as a multicriterion decision-making (MCDM) problem.

From literature review, many MCDM techniques have been developed to address the selection problem considering multiple criteria, such as preference selection index (PSI) [6], graph theory and matrix representation approach (GTMA) [7], preference ranking organization method for enrichment evaluation (PROMETHEE) [8, 9], grey relational analysis (GRA) [10-12], technique for order preference by similarity to ideal solution (TOPSIS) [13], elimination and choice translating reality (ELECTRE) [14, 15], Vlse Kriterijumska Optimizacija Kompromisno Resenje (VIKOR) [16, 17], and analytic hierarchy process (AHP) $[18,19]$. Moreover, the combination of these methods is the most noteworthy.

On the basis of these MCDM methods and commercial manufacture, a series of scientific and systemic theoretical explorations, on the issue of material evaluation and selection, have been reported in recent years. After conducting the analysis of cons and pros of them, we have used a mixed approach with the combination of AHP, used to determine the weight of indicators, and GRA, applied to build the grey relational closeness index to evaluate the scheme, for the optimization of lightweight material selection for car bodies. Finally, after calculation, we have concluded that the alternative of aluminum alloy is the optimal choice among ten alternatives.

The rest of this paper is organized as follows: the second section summarizes some related literature. The third part depicts the solution methodology. In addition, the case study is carried out in the fourth section, and then analysis and discussion are conducted. The last part sums up some conclusions and discusses the completion of this work.

\section{Literature Review}

Methodologies considering MCDM problems developed and applied by prior scholars are generally displayed in this part. In general, these methods which aim to address the MCDM problems could be generalized into the following two types. The first type is synthetic evaluation methods, such as preference ranking organization method for enrichment evaluation (PROMETHEE) $[8,9]$, grey relational analysis (GRA) [10-12], technique for order preference by similarity to ideal solution (TOPSIS) [13], ELimination and Choice Expressing the REality (ELECTRE) [14, 15], Vlse Kriterijumska Optimizacija Kompromisno Resenje (VIKOR) [16, 17], AHP [18, 19], best-worst method (BWM) [20], decision-making trial and evaluation laboratory (DEMATEL) [21], and grey correlation (GC) [10, 22, 23]. And the second one is established on the basement of lifecycle assessment (LCA) [24]. In addition, for the purpose of dealing with shortcomings of single approach, researchers have been trying to propose some integrated methods, and these newly developed approaches have demonstrated some successful application. For example, Peter et al. [25] combined the fuzzy synthetic extent analysis method and fuzzy extended AHP to get the ultimate rank/priority of each criterion. Liu et al. [26] proposed a mixed MCDM method with integration of modified VIKOR and DEMATEL-based ANP (analytical network process), for the enhancement of the dependability of the calculation results, aiming to help project planners handle the problem of the correlation analysis absence among criteria for the process of material selection. For the material selection problem of highly sensitive components, Shanian and Savadogo [27] used MCDM method to address it.

Studies about the MCDM problem have been implemented a lot as listed above. There are also lots of research studies, especially in the area of optimal lightweight material selection of vehicles.

$\mathrm{Pu}$ et al. [28] put forward a comprehensive hierarchical structure with systematic multiperspective indices and applied a hybrid approach with integration of grey relational analysis (GRA) and technique for order preference by similarity to ideal solution (TOPSIS) for the determination of optimal lightweight material for vehicles. Xiong et al. [29] presented an approach combining grey relational and principal component analysis for lightweight optimization of the side structure of the automobile body. Mayyas et al. [30] used multiattribute decision-making tools, quality function deployment (QFD) and analytic hierarchy process (AHP), which select optimal material for automotive bodyin-white (BIW) panels. Yang et al. [31] adopted the fuzzy technique for order preference by similarity to ideal solution (fuzzy TOPSIS) for the evaluation of the qualification of the candidate materials for two automotive case studies, including an engine block and an intake manifold, were carried out to demonstrate applicability of the methodology. Mayyas et al. [32] developed an eco-material selection approach which was assisted by the preference selection index (PSI) and principal component analysis (PCA) decisionmaking tools and implemented this model in a case study of 
material selection for eco-lightweight autobodies to validate its practicality.

\section{Solution Methodology}

In this paper, we developed a method that combines the advantages of AHP which determines the weight of indicators and the advantages of GRA which is used to build the grey relational closeness index to evaluate the scheme. This method was put forward and used to the optimization of lightweight material selection for car bodies. The detailed procedure is presented in the following sections.

\subsection{Hierarchical Structure of Lightweight Material Selection} for Automobile Application. According to the expert interview and related literature, four criterion levels and their factor levels are given. We set up a system of indicators for lightweight material selection, which is shown in Figure 1 and includes three levels, i.e., goal level, criterion level, and factor/attribute level. The goal level (B) is lightweight material selection for automobile applications. The criterion level (A) includes four aspects, i.e., physical properties (A1), durability $\left(A_{2}\right)$, technical $\left(A_{3}\right)$, and environment $\left(A_{4}\right)$. Physical properties include four factors, i.e., density $\left(E_{1}\right)$, modulus of elasticity $\left(\mathrm{E}_{2}\right)$, tensile strength $\left(\mathrm{E}_{3}\right)$, and weight $\left(\mathrm{E}_{4}\right)$. Durability includes three factors, i.e., corrosion resistance $\left(E_{5}\right)$, thermal performance $\left(E_{6}\right)$, and wear resistance $\left(E_{7}\right)$. Technology includes three factors, i.e., forming $\left(E_{8}\right)$, joining $\left(\mathrm{E}_{9}\right)$, and painting $\left(\mathrm{E}_{10}\right)$. Environment includes three factors, i.e., embodied energy performance $\left(\mathrm{E}_{11}\right), \mathrm{CO}_{2}$ emission-form extraction and production performance $\left(\mathrm{E}_{12}\right)$, and recycle fraction $\left(\mathrm{E}_{13}\right)$.

3.2. Analytic Hierarchy Process (AHP). Analytic hierarchy process (AHP) was proposed for the first time by Saaty [18]. It is one sort of multicriterion decision-making methods referring to quantitative and qualitative analysis. The AHP method consists of three bases: (1) construct a hierarchy, (2) set the priority, and (3) logical consistency. Its basic steps are shown as follows:

Step 1: construct a hierarchy.

Step 2: set the priority. The base scale can be used to shorten the expression of preference degree as shown in Table 1.

Step 3: build the evaluation matrix. This involves using the $k$-order evaluation matrix $A$ with pairwise values and each element $a_{i j}, i$, and $j \in\{1,2, \ldots, k\}$ to define the expert's individual preference of the alternative $A_{j}$ for the alternative $A_{i}$, as shown below:

$$
\begin{aligned}
A & =\left[a_{i j}\right], \quad(i=1,2, \ldots, k ; j=1,2, \ldots, k), \\
a_{i i} & =1, a_{i j}>0 \\
a_{j i} & =\frac{1}{a_{i j}} .
\end{aligned}
$$

In addition, Table 2 shows the random consistency index RI. It is used to eliminate the effects of different “ $k$ " effects.

Step 4: obtain the standard weights. The vector of weights $w=\left(w_{1}, w_{2}, \ldots, w_{k}\right)$ can be obtained from the pairwise comparison matrix $A$ used:

$$
A w=\lambda_{\max } w
$$

where $w$ is the vector according to the maximal eigenvalue $\lambda_{\max }$ of matrix $A$.

Step 5: check consistency. Compute the final Consistency Ratio (CR) by

$$
\begin{aligned}
\mathrm{CI} & =\frac{-1}{k-1} \sum_{k-2}^{k} \lambda_{i}=\frac{\lambda_{\max }-k}{(k-1)}, \\
\mathrm{CR} & =\frac{\mathrm{CI}}{\mathrm{RI}}
\end{aligned}
$$

where $\mathrm{CI}$ is the consistency index and RI is the random consistency index. The higher the CI value, the smaller the degree of consistency of the comparison matrix. If $\mathrm{CR}<0.1$, the judgment matrix can be accepted. Thus, to obtain a consistent matrix, it is necessary to evaluate and adjust it until $\mathrm{CR}<0.1$.

3.3. Grey Relational Analysis (GRA). GRA is a MCDM method that evaluates alternatives using the grey relational closeness index [9]. If an alternative has a really large grey correlation within its ideal alternative, it can be seen as close to the ideal. Therefore, the grey correlation index can be applied to choose the lightweight material of a car body between the positive- and negative-ideal solutions $[17,18]$. The GRA method includes the following steps:

Step 1: constructing a decision matrix to evaluate the chosen materials. The decision matrix $X=\left[x_{i j}\right]_{n \times m}$ can be written as

$$
\begin{aligned}
& \begin{array}{lllll}
B_{1} & \cdots & B_{j} & \cdots & B_{m}
\end{array} \\
& X=\begin{array}{c}
A_{1} \\
\vdots \\
A_{i} \\
\vdots \\
A_{n}
\end{array}\left[\begin{array}{ccccc}
x_{11} & \cdots & x_{1 j} & \cdots & x_{1 m} \\
\vdots & \ddots & \vdots & \ddots & \vdots \\
x_{i 1} & \cdots & x_{i j} & \cdots & x_{i m} \\
\vdots & \ddots & \vdots & \ddots & \vdots \\
x_{n 1} & \cdots & x_{n j} & \cdots & x_{n m}
\end{array}\right] \text {, }
\end{aligned}
$$

where $x_{i j}$ is a clear value representing the performance level of each alternative $A_{i}(i=1,2, \ldots, n)$ for each criterion $B_{j}(j=1,2, \ldots, m)$.

Step 2: the normalized decision matrix $Z$ is gotten by combining the weight vectors of the standard $\omega$, which is computed by the above AHP method: 


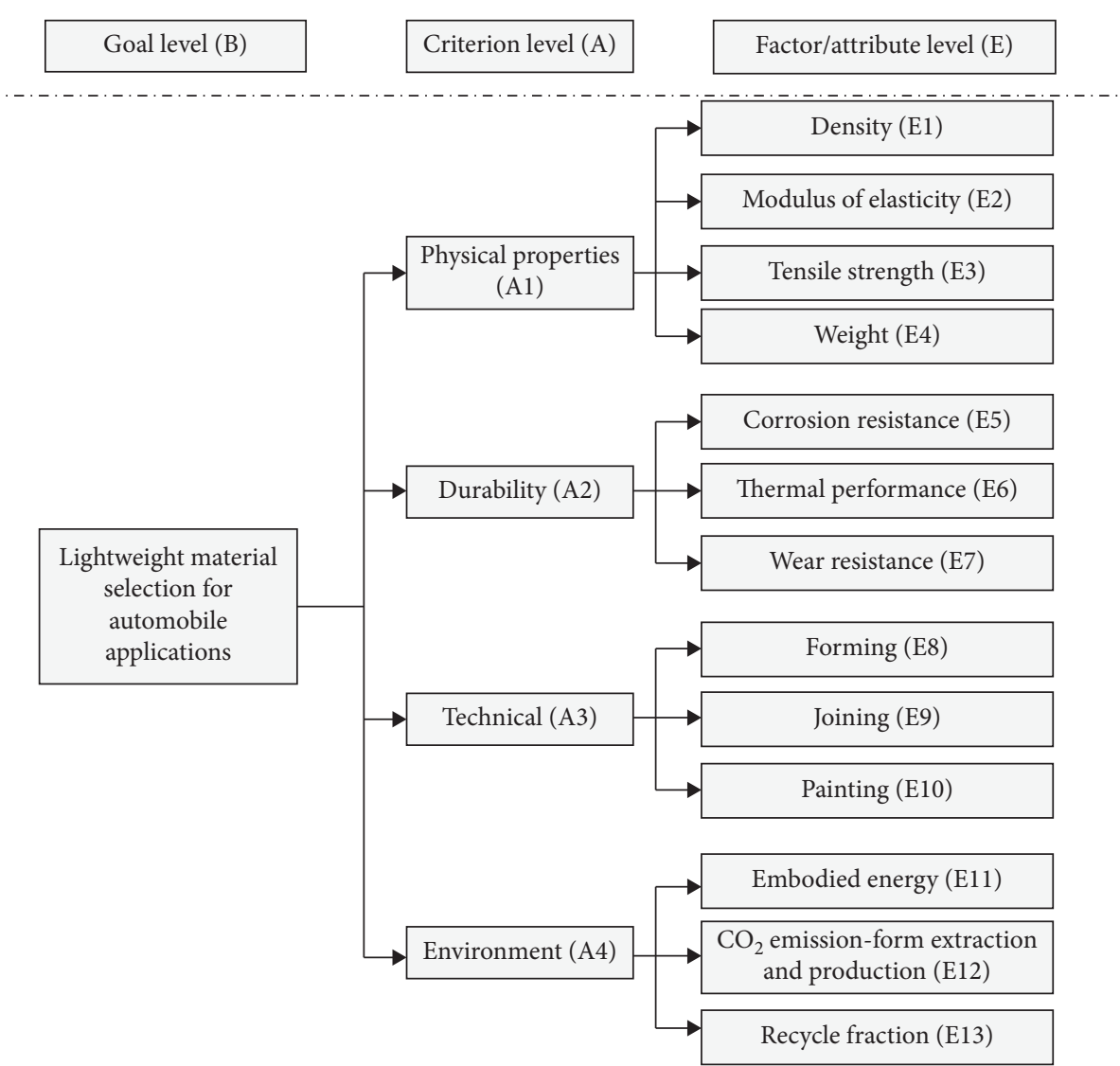

Figure 1: System of indicators for lightweight material selection.

$y_{i j}=\frac{x_{i j}}{\max _{i} x_{i j}}, \quad(i=1,2, \ldots, n ; j=1,2, \ldots, m)$,

$$
\begin{aligned}
& \begin{array}{llllll}
B_{1} & \cdots & B_{j} & \cdots & B_{m}
\end{array} \\
& Z=\omega^{T} Y=\begin{array}{c}
A_{1} \\
\vdots \\
A_{i} \\
\vdots \\
A_{n}
\end{array}\left[\begin{array}{ccccc}
\omega_{1}^{\prime} y_{11} & \cdots & \omega_{j}^{\prime} y_{1 j} & \cdots & \omega_{m}^{\prime} y_{1 m} \\
\vdots & \ddots & \vdots & \ddots & \vdots \\
\omega_{1}^{\prime} y_{i 1} & \cdots & \omega_{j}^{\prime} y_{i j} & \cdots & \omega_{m}^{\prime} y_{i m} \\
\vdots & \ddots & \vdots & \ddots & \vdots \\
\omega_{1}^{\prime} y_{n 1} & \cdots & \omega_{j}^{\prime} y_{n j} & \cdots & \omega_{m}^{\prime} y_{n m}
\end{array}\right] .
\end{aligned}
$$

Step 3: establishing the positive- and negative-ideal solutions. It can be solved by

$$
\begin{aligned}
& Z^{+}=\left[z_{j}^{+}\right]_{1 \times m}=\left[\max _{i}\left(\left\{z_{i j}\right\}_{i=1}^{n}\right)\left|j \in J^{+}, \min _{i}\left(\left\{z_{i j}\right\}_{i=1}^{n}\right)\right| j \in J^{-}\right]_{1 \times m}, \\
& Z^{-}=\left[z_{j}^{-}\right]_{1 \times m}=\left[\min _{i}\left(\left\{z_{i j}\right\}_{i=1}^{n}\right)\left|j \in J^{+}, \max _{i}\left(\left\{z_{i j}\right\}_{i=1}^{n}\right)\right| j \in J^{-}\right]_{1 \times m},
\end{aligned}
$$

where $J^{+}$means an index set which larger is better and $J^{-}$means an index set which smaller is better.
Step 4: calculating the grey relational coefficient between the $i$ th scheme and the ideal solutions for the $j$ th criteria, shown as follows:

$r_{i j}^{+}=\frac{\min _{i} \min _{j}\left|z_{j}^{+}-z_{i j}\right|+\rho \max _{i} \max _{j}\left|z_{j}^{+}-z_{i j}\right|}{\left|z_{j}^{+}-z_{i j}\right|+\rho \max _{i} \max _{j}\left|z_{j}^{+}-z_{i j}\right|}$,

where $\rho \in[0,1]$ means the resolution factor. As usual, $\rho=0.5$.

The grey relational coefficient matrix, shown in equation (12), is used for each alternative and positiveideal solution:

$$
\begin{gathered}
B_{1} \\
R^{+}= \\
A_{1} \\
\vdots \\
A_{i} \\
\vdots \\
A_{n}
\end{gathered} \quad\left[\begin{array}{ccccc}
r_{11}^{+} & \cdots & r_{1 j}^{+} & \cdots & r_{1 m}^{+} \\
\vdots & \ddots & \vdots & \ddots & \vdots \\
r_{i 1}^{+} & \cdots & r_{i j}^{+} & \cdots & r_{i m}^{+} \\
\vdots & \ddots & \vdots & \ddots & \vdots \\
r_{n 1}^{+} & \cdots & r_{n j}^{+} & \cdots & r_{n m}^{+}
\end{array}\right] .
$$

The grey relational degree between the $i$ th scheme and the positive-ideal solution can be computed by 
TABLE 1: AHP scale for combinations.

\begin{tabular}{|c|c|c|}
\hline Numerical rating & Definition & Explanation \\
\hline 1 & Equally preferred & Two activities contribute equally to the objective \\
\hline 3 & Moderately preferred & Experience and judgment slightly favour one over another \\
\hline 5 & Strongly preferred & Experience and judgment strongly favour one over another \\
\hline 7 & Very strongly preferred & An activity is strongly favoured and its dominance is demonstrated in practice \\
\hline 9 & Absolutely preferred & Importance of one over another affirmed on the highest possible order \\
\hline $2,4,6$, and 8 & Intermediate values & Used to represent compromise between the priorities listed above \\
\hline Reciprocals $\left(1 / a_{i j}\right)$ & A value attributed whe & ity $i$ is compared to activity $j$ becomes the reciprocal when $j$ is compared to $i$ \\
\hline
\end{tabular}

$$
R_{i}^{+}=\frac{1}{m} \sum_{j=1}^{m} r_{i j}^{+}, \quad(i=1,2, \ldots, n) .
$$

Step 5: in the same way, the grey relational coefficient between the $i$ th alternative and the negativeideal solution for the $j$ th index can be gotten by Step 4:

$r_{i j}^{-}=\frac{\min _{i} \min _{j}\left|z_{j}^{-}-z_{i j}\right|+\rho \max _{i} \max _{j}\left|z_{j}^{-}-z_{i j}\right|}{\left|z_{j}^{-}-z_{i j}\right|+\rho \max _{i} \max _{j}\left|z_{j}^{-}-z_{i j}\right|}$.

Grey relational coefficient matrix, shown as equation (15), is used for each alternative and the negative-ideal solution:

$$
R^{-}=\begin{array}{ccccc}
B_{1} & \cdots & B_{j} & \cdots & B_{m} \\
A_{1} & \vdots \\
A_{i} & {\left[\begin{array}{ccccc}
r_{11}^{-} & \cdots & r_{1 j}^{-} & \cdots & r_{1 m}^{-} \\
\vdots & \ddots & \vdots & \ddots & \vdots \\
r_{i 1}^{-} & \cdots & r_{i j}^{-} & \cdots & r_{i m}^{-} \\
\vdots & \ddots & \vdots & \ddots & \vdots \\
A_{n} & \cdots & r_{n j}^{-} & \cdots & r_{n m}^{-}
\end{array}\right] .}
\end{array}
$$

The grey relational degree between the $i$ th scheme and the negative-ideal solution can be gotten by

$$
R_{i}^{-}=\frac{1}{m} \sum_{j=1}^{m} r_{i j}^{-}, \quad(i=1,2, \ldots n) .
$$

Step 6: the index of approximation of grey correlation $R_{i}$ for the $i$ th alternative is obtained as follows:

$$
R_{i}=\frac{R_{i}^{+}}{R_{i}^{+}+R_{i}^{-}}, \quad(i=1,2, \ldots, n) .
$$

\section{Case Study}

To verify the hierarchical structure given above and this MCDM method, a case study, i.e., ten kinds of automotive tailgate materials for a car body, is carried out in the following.

4.1. Data Collection. Recently, the quality of traditional materials has been improved with the advancement and improvement of the study material science, resulting in much more expanding area of material application.
Moreover, composite materials have also been developing rapidly and applied presently in a wide range of different fields. For instance, in the area of automobile industry, lots of advanced and practical materials have been applied to cut down the quantity of a car body, such as aluminum alloy and high-strength steel. On the basis of information collected from the literature and experts, ten kinds of automotive tailgate materials, i.e., steels $\left(S_{1}\right)$, aluminum alloy $\left(\mathrm{S}_{2}\right)$, sheet molding compound $\left(\mathrm{S}_{3}\right)$, lightweight sheet molding compound $\left(\mathrm{S}_{4}\right)$, polypropylene $\left(\mathrm{S}_{5}\right)$, GMT $\left(\mathrm{S}_{6}\right)$, PP-LGF $\left(S_{7}\right)$, thermoplastics polyolefin $\left(S_{8}\right)$, carbon fiber/ epoxy composites $\left(\mathrm{S}_{9}\right)$, and S-glass fiber/epoxy composites $\left(\mathrm{S}_{10}\right)$, are taken into consideration, for demonstrating the practicability of this newly designed hierarchical structure and the presented MCDM method of this research. In addition, we interviewed two experienced senior engineers who come from an automobile manufacture enterprise which is really reputable, as well as four decision-makers including two experts who have been specializing in automobile design for many years. That is used to obtain the original data and some initial information that is relevant, through the way of questionnaire investigation. We conduct the whole process of this investigation between June 21 and 28 in 2018. And we resurveyed for the improved criterion system from Aug 28 to 31 in 2019.

4.2. Determination of the Weight of Each Criterion. On the basis of the results of expert interview, the pairwise matrix (Table 3) was established by us from physical, durability, technical, and environment properties. Similarly, we establish the pairwise matrix from physical property $\left(A_{1}-E\right)$, from durability property $\left(\mathrm{A}_{2}-\mathrm{E}\right)$, from technical property $\left(A_{3}-E\right)$, and from environment property $\left(A_{4}-E\right)$, which are presented in Tables 4-7, respectively.

For the hierarchical structure, the weight vector of each criterion and the value of CR can be computed, following the calculation process of AHP by equations (1)-(5). The importance of each criterion and its CR of each material and the ultimate weight vector of criteria on the overall goal of the evaluation index can be obtained, which is presented in Table 8 .

4.3. Evaluation of Three Auto Parts Manufacturing Companies. The scores of each criterion for ten kinds of automotive tailgate materials for a car body are listed in Table 9. The ultimate ranking orders of the value $R_{i}$ can be acquired via the calculation process of this MCDM 
TABLE 2: Random consistency index (RI).

\begin{tabular}{lcccccccccc}
\hline$k$ & 1 & 2 & 3 & 4 & 5 & 6 & 7 & 8 & 9 & 10 \\
\hline RI & 0 & 0 & 0.58 & 0.9 & 1.12 & 1.24 & 1.32 & 1.41 & 1.45 & 1.49 \\
\hline
\end{tabular}

TABLe 3: The pairwise matrix from physical, durability, technical, and environmental properties (B-A).

\begin{tabular}{ccccc}
\hline & $\mathrm{A}_{1}$ & $\mathrm{~A}_{2}$ & $\mathrm{~A}_{3}$ & $\mathrm{~A}_{4}$ \\
\hline $\mathrm{A}_{1}$ & 1 & 3 & 2 & 2 \\
$\mathrm{~A}_{2}$ & $1 / 3$ & 1 & 2 & 3 \\
$\mathrm{~A}_{3}$ & $1 / 2$ & $1 / 2$ & 1 & 2 \\
$\mathrm{~A}_{4}$ & $1 / 2$ & 3 & 2 & 1 \\
\hline
\end{tabular}

TABLE 4: The pairwise matrix from physical property $\left(A_{1}-E\right)$.

\begin{tabular}{ccccc}
\hline & $\mathrm{E}_{1}$ & $\mathrm{E}_{2}$ & $\mathrm{E}_{3}$ & $\mathrm{E}_{4}$ \\
\hline $\mathrm{E}_{1}$ & 1 & 4 & 3 & 6 \\
$\mathrm{E}_{2}$ & $1 / 4$ & 1 & $1 / 2$ & 3 \\
$\mathrm{E}_{3}$ & $1 / 3$ & 2 & 1 & 4 \\
$\mathrm{E}_{4}$ & $1 / 6$ & $1 / 3$ & $1 / 4$ & 1 \\
\hline
\end{tabular}

TABle 5: The pairwise matrix from durability property $\left(\mathrm{A}_{2}-\mathrm{E}\right)$.

\begin{tabular}{cccc}
\hline & $\mathrm{E}_{5}$ & $\mathrm{E}_{6}$ & $\mathrm{E}_{7}$ \\
\hline $\mathrm{E}_{5}$ & 1 & $1 / 2$ & 2 \\
$\mathrm{E}_{6}$ & 2 & 1 & 3 \\
$\mathrm{E}_{7}$ & $1 / 2$ & $1 / 3$ & 1 \\
\hline
\end{tabular}

TABle 6: The pairwise matrix from technical property $\left(A_{3}-E\right)$.

\begin{tabular}{lccc}
\hline & $\mathrm{E}_{8}$ & $\mathrm{E}_{9}$ & $\mathrm{E}_{10}$ \\
\hline $\mathrm{E}_{8}$ & 1 & 3 & $1 / 2$ \\
$\mathrm{E}_{9}$ & $1 / 3$ & 1 & $1 / 4$ \\
$\mathrm{E}_{10}$ & 2 & 4 & 1 \\
\hline
\end{tabular}

TABLE 7: The pairwise matrix from environmental property $\left(A_{4}-E\right)$.

\begin{tabular}{lccc}
\hline & $\mathrm{E}_{11}$ & $\mathrm{E}_{12}$ & $\mathrm{E}_{13}$ \\
\hline $\mathrm{E}_{11}$ & 1 & $1 / 2$ & $1 / 4$ \\
$\mathrm{E}_{12}$ & 2 & 1 & $1 / 3$ \\
$\mathrm{E}_{13}$ & 4 & 3 & 1 \\
\hline
\end{tabular}

method, i.e., GRA. Hence, we can select the final optimal alternative according to the results. Note that the index set for which the smaller the better includes density and weight; the index system for which the greater the better includes modulus of elasticity, tensile strength, corrosion resistance, thermal performance, wear resistance, forming, joining, painting, embodied energy performance, $\mathrm{CO}_{2}$ emission-form extraction and production performance, and recycle fraction. The specific procedure for the assessment of empirical example, i.e., ten kinds of automotive tailgate materials, is shown below:
TABLE 8: The weight of each criterion.

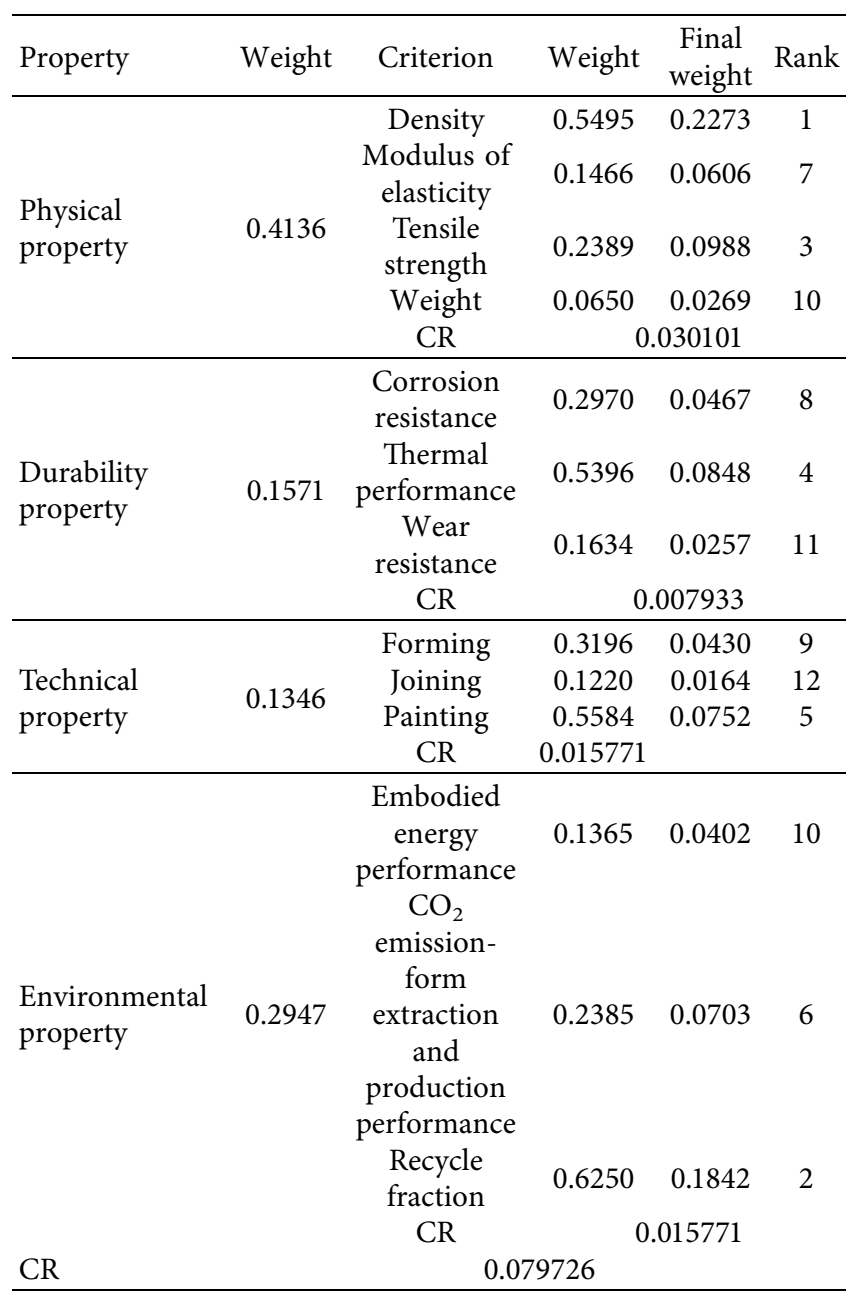

The initial decision matrix $X$ can be obtained by Table 9. Note that $x_{i j}$ indicates the value of each alternative $\mathrm{A}_{i}$ $(i=1,2, \ldots, 10)$ with respect to each evaluation criterion $\mathrm{B}_{j}$ $(j=1,2, \ldots, 13)$. Then, the normalized decision matrix combined with the weight vector of criteria $\omega$ can be calculated by equations (6)-(8). In practice counting, the values of rows of $E_{1}$ and $E_{4}$ are computed as their reciprocals, because criteria $\mathrm{E}_{1}$ and $\mathrm{E}_{4}$ are negative volume indices, which means that the smaller the values, the higher the scores and the better the performance. The positive-ideal and negative-ideal solutions can be obtained according to equations (9) and (10). The grey correlation coefficient between the alternative and positive-ideal/negative-ideal alternative regarding each criterion can be calculated by equations (11)-(16) as shown in Table 10. Finally, the final rank of each alternative can be obtained by the values of $R_{i}(i=1,2, \ldots, 10)$, which are calculated by equation (17).

Based on the process of calculation, we concluded that the alternative 2, i.e., aluminum alloy, is the best alternative for a car body among ten materials investigated. 
TABLE 9: The score of each criterion for ten kinds of automotive tailgate materials.

\begin{tabular}{lccccccccccccc}
\hline & $\mathrm{E}_{1}$ & $\mathrm{E}_{2}$ & $\mathrm{E}_{3}$ & $\mathrm{E}_{4}$ & $\mathrm{E}_{5}$ & $\mathrm{E}_{6}$ & $\mathrm{E}_{7}$ & $\mathrm{E}_{8}$ & $\mathrm{E}_{9}$ & $\mathrm{E}_{10}$ & $\mathrm{E}_{11}$ & $\mathrm{E}_{12}$ & $\mathrm{E}_{13}$ \\
\hline $\mathbf{S}_{\mathbf{1}}$ & 7.85 & 210 & 340 & 6.28 & 6 & 9 & 9 & 8 & 9 & 8 & 6 & 7 & 7 \\
$\mathbf{S}_{\mathbf{2}}$ & 2.80 & 70 & 240 & 3.64 & 5 & 9 & 9 & 9 & 9 & 9 & 9 & 9 \\
$\mathbf{S}_{\mathbf{3}}$ & 1.85 & 10.5 & 70 & 5.18 & 9 & 6 & 7 & 8 & 7 & 9 & 8 & 7 \\
$\mathbf{S}_{\mathbf{4}}$ & 1.45 & 22 & 65 & 4.06 & 8 & 6 & 7 & 7 & 7 & 9 & 8 & 5 & 8 \\
$\mathbf{S}_{\mathbf{5}}$ & 0.90 & 1.6 & 35 & 2.52 & 9 & 5 & 7 & 8 & 7 & 9 & 7 & 7 & 5 \\
$\mathbf{S}_{\mathbf{6}}$ & 1.22 & 5.5 & 76.7 & 3.42 & 9 & 6 & 7 & 8 & 7 & 9 & 7 & 7 & 7 \\
$\mathbf{S}_{\mathbf{7}}$ & 1.20 & 9.5 & 140 & 3.36 & 9 & 6 & 8 & 8 & 7 & 8 & 6 & 8 \\
$\mathbf{S}_{\mathbf{8}}$ & 0.91 & 1.4 & 17.5 & 2.55 & 9 & 5 & 7 & 8 & 7 & 9 & 8 & 7 \\
$\mathbf{S}_{\mathbf{9}}$ & 1.61 & 115 & 1400 & 2.98 & 9 & 5 & 7 & 7 & 6 & 8 & 7 & 7 \\
$\mathbf{S}_{\mathbf{1 0}}$ & 1.83 & 23.8 & 448.8 & 3.51 & 9 & 5 & 7 & 7 & 6 & 8 & 7 & 7 \\
\hline
\end{tabular}

TABLe 10: The values of $R^{+}$and $R^{-}$.

\begin{tabular}{lllr}
\hline & $R^{+}$ & $R^{-}$ & $R$ \\
\hline Steels & 0.8481 & 0.7889 & 0.5181 \\
Aluminum alloy & 0.8571 & 0.7765 & 0.5247 \\
Sheet molding compound & 0.7511 & 0.7941 & 0.4861 \\
Lightweight SMC & 0.7232 & 0.8358 & 0.4639 \\
Polypropylene & 0.7794 & 0.8791 & 0.4699 \\
GMT & 0.7419 & 0.8356 & 0.4703 \\
PP-LGF & 0.7295 & 0.8412 & 0.4645 \\
Thermoplastics polyolefin & 0.8073 & 0.8599 & 0.4842 \\
Carbon fiber/epoxy composites & 0.7913 & 0.8088 & 0.4945 \\
S-glass fiber/epoxy composites & 0.7329 & 0.8438 & 0.4648 \\
\hline
\end{tabular}

\section{Conclusions}

Selecting the lightweight material for a car body is a difficult and restrained issue for the automobile manufacturers, due to the requirement of multiple-objective consideration. In this work, we formulated a hierarchical structure with four targets, including physical properties, durability, technical, and environment. Each of four targets includes several second-level indices. Furthermore, we presented a hybrid MCDM approach integrating GRA and AHP to handle the disadvantages of just using a single method. An empirical case study of ten kinds of automotive tailgate materials was illustrated. The results validated the reliability of the proposed hybrid approach. Moreover, the obtained weight of each criterion plays a significant role reasonably and scientifically in the selection of the lightweight material. Therefore, it can be conclude that the hybrid approach is a reliable and effective tool for the issue of lightweight material selection.

Our studies will concentrate on the following two aspects in the future: (1) taking other critical influences into consideration, for instance, societal or economic factors, and creating a more comprehensive hierarchical structure for the problem of material selection; (2) due to the existence of the uncertain and fuzzy feature of information obtained from experts in the decision matrix, uncertain theory might need to be applied in our work to fill the gap and complete our research [33-35].

\section{Data Availability}

The data used to support the findings of this study are available from the corresponding author upon request.

\section{Conflicts of Interest}

The authors declare that they have no conflicts of interest.

\section{References}

[1] G. Tian, X. Liu, M. Zhang et al., "Selection of take-back pattern of vehicle reverse logistics in China via Grey-DEMATEL and Fuzzy-VIKOR combined method," Journal of Cleaner Production, vol. 220, no. 5, pp. 1088-1100, 2019.

[2] http://www.vecc.org.cn/180601/1-1P601164953.pdf.

[3] H. M. Zhu, "The application and development of key technologies in automotive weight lightening," Applied Energy Technology, no. 2, pp. 10-13, 2009.

[4] Z. J. Wang, S. P. Chen, Y. Z. Zhao et al., "High strength steel promotes lightweight in body in white," Modern Components, no. 3, pp. 82-84, 2014.

[5] S. Q. Ying, J. Zhang, J. S. Wang et al., "The study of automotive lightweight technology," Automobile Technology \& Material, no. 2, pp. 1-4, 2010.

[6] K. Maniya and M. G. Bhatt, "A selection of material using a novel type decision-making method: preference selection index method," Materials \& Design, vol. 31, no. 4, pp. 1785-1789, 2010.

[7] V. Jain and T. Raj, "Modeling and analysis of FMS performance variables by ISM, SEM and GTMA approach," International Journal Of Production Economics, vol. 171, no. 1, pp. 84-96, 2016.

[8] M. Behzadian, R. B. Kazemzadeh, A. Albadvi, and M. Aghdasi, "PROMETHEE: a comprehensive literature review on methodologies and applications," European Journal of Operational Research, vol. 200, no. 1, pp. 198-215, 2010.

[9] J. P. Brans, B. Mareschal, and P. Vincke, "PROMETHEE: a new family of outranking methods in multicriteria analysis," 
in Operational Research, J. P. Brans, Ed., pp. 477-490, Université libre de Bruxelles, Brussels, Belgium, 1984.

[10] L.-Y. Zhai, Li-P. Khoo, and Z.-W. Zhong, "Design concept evaluation in product development using rough sets and grey relation analysis," Expert Systems with Applications, vol. 36, no. 5, pp. 5649-5657, 2012.

[11] C. L. Hwang and K. Yoon, "Multiple attribute decision making: a state of the art survey," in Lecture Notes in Economics and Mathematical Systems, Vol. 186, Springer-Verlag, Berlin, Germany, 1981.

[12] W. Yang and Y. Wu, "A novel TOPSIS method based on improved grey relational analysis for multiattribute decisionmaking problem," Mathematical Problems in Engineering, vol. 2019, Article ID 8761681, 10 pages, 2019.

[13] S. Opricovic and G.-H. Tzeng, "Compromise solution by MCDM methods: a comparative analysis of VIKOR and TOPSIS," European Journal Of Operational Research, vol. 156, no. 2, pp. 445-455, 2004.

[14] H. Hashemi, S. Mousavi, E. Zavadskas, A. Chalekaee, and Z. Turskis, "A new group decision model based on greyintuitionistic fuzzy-ELECTRE and VIKOR for contractor assessment problem," Sustainability, vol. 10, no. 5, p. 1635 , 2018.

[15] B. Roy, "The outranking approach and the foundations of ELECTRE methods," Theory and Decision, vol. 31, no. 1, pp. 49-73, 1991.

[16] A. Jahan, F. Mustapha, M. Y. Ismail, S. M. Sapuan, and M. Bahraminasab, "A comprehensive VIKOR method for material selection," Materials \& Design, vol. 32, no. 3, pp. 1215-1221, 2011.

[17] S. Opricovic, Multiple Criteria Optimization of Civil Engineering Systems, Faculty of Civil Engineering, Belgrade, Serbia, 1998.

[18] T. L. Saaty, "A scaling method for priorities in hierarchical structures," Journal of Mathematical Psychology, vol. 15, no. 3, pp. 234-281, 1977.

[19] Z. Turskis, E. K. Zavadskas, J. Antucheviciene, and N. Kosareva, "A hybrid model based on fuzzy AHP and fuzzy WASPAS for construction site selection," International Journal of Computers Communications \& Control, vol. 10, no. 6, pp. 113-128, 2015.

[20] J. Rezaei, "Best-worst multi-criteria decision-making method," Omega, vol. 53, pp. 49-57, 2015.

[21] S. Altuntas, H. Selim, and T. Dereli, "A fuzzy DEMATELbased solution approach for facility layout problem: a case study," The International Journal of Advanced Manufacturing Technology, vol. 73, no. 5-8, pp. 749-771, 2014.

[22] J. W. K. Chan, "Application of grey relational analysis for ranking material options," International Journal of Computer Applications in Technology, vol. 26, no. 4, pp. 210-217, 2006.

[23] J. W. K. Chan and T. K. L. Tong, "Multi-criteria material selections and end-of-life product strategy: grey relational analysis approach," Materials \& Design, vol. 28, no. 5, pp. 1539-1546, 2007.

[24] P. Peças, I. Ribeiro, A. Silva, and E. Henriques, "Comprehensive approach for informed life cycle-based materials selection," Materials \& Design, vol. 43, pp. 220-232, 2013.

[25] O. A. Peter, O. O. Paul, and A. C. Ezekiel, "Multi-criteria evaluation model for the selection of sustainable materials for building projects," Automation in Construction, vol. 30, pp. 113-125, 2013.

[26] H.-C. Liu, J.-X. You, L. Zhen, and X.-J. Fan, "A novel hybrid multiple criteria decision making model for material selection with target-based criteria," Materials \& Design, vol. 60, pp. 380-390, 2014.

[27] A. Shanian and O. Savadogo, "A methodological concept for material selection of highly sensitive components based on multiple criteria decision analysis," Expert Systems with Applications, vol. 36, no. 2, pp. 1362-1370, 2009.

[28] Y. Pu, F. Ma, J. Zhang, and M. Yang, "Optimal lightweight material selection for automobile applications considering multi-perspective indices," IEEE Access, vol. 6, pp. 8591-8598, 2018.

[29] F. Xiong, D. Wang, S. Zhang, K. Cai, S. Wang, and F. Lu, "Lightweight optimization of the side structure of automobile body using combined grey relational and principal component analysis," Structural \& Multidisciplinary Optimization, vol. 1, pp. 1-21, 2017.

[30] A. Mayyas, Q. Shen, A. Mayyas et al., "Using quality function deployment and analytical hierarchy process for material selection of body-in-white," Materials \& Design, vol. 32, no. 5, pp. 2771-2782, 2011.

[31] S. S. Yang, N. Nasr, S. K. Ong, and A. Y. C. Nee, “Designing automotive products for remanufacturing from material selection perspective," Journal of Cleaner Production, vol. 153, pp. 570-579, 2015.

[32] A. T. Mayyas, A. Qattawi, A. R. Mayyas, and M. Omar, "Quantifiable measures of sustainability: a case study of materials selection for eco-lightweight auto-bodies," Journal of Cleaner Production, vol. 40, no. 3, pp. 177-189, 2013.

[33] G. Tian, M. Zhou, and P. Li, "Disassembly sequence planning considering fuzzy component quality and varying operational cost," IEEE Transactions on Automation Science and Engineering, vol. 15, no. 2, pp. 748-760, 2018.

[34] G. Tian, Y. Ren, Y. Feng, M. Zhou, H. Zhang, and J. Tan, "Modeling and planning for dual-objective selective disassembly using AND/OR graph and discrete artificial bee colony," IEEE Transactions on Industrial Informatics, vol. 15, no. 4, pp. 2456-2468, 2019.

[35] G. Tian, N. Hao, M. Zhou et al., "Fuzzy grey choquet integral for evaluation of multicriteria decision making problems with interactive and qualitative indices," IEEE Transactions on Systems, Man, and Cybernetics: Systems, pp. 1-14, 2019. 